\title{
Bias and dispersal in the animal reintroduction literature
}

\author{
Bálint Bajomi, Andrew S. Pullin, Gavin B. Stewart and \\ ANDRÁs TAKÁCS - SÁn T A
}

\begin{abstract}
We examined the literature on animal reintroductions to assess the challenges facing individual conservation practitioners who wish to access, synthesize and interpret available evidence to inform their decision making. We undertook an extensive search in eight electronic literature databases, using seven different keyword combinations, and added the content of four bibliographies on reintroductions. We found 3,826 potentially relevant publications totalling at least 29,290 pages of text. Taxonomic bias is apparent in the distribution of general and conservation scientific literature and in reintroduction programmes. We examined whether the literature on reintroductions is biased in a similar way. Comparing the distribution of reintroduction publications to numbers of species, reintroduction programmes and the general conservation literature, there is a marked taxonomic bias favouring vertebrates, especially birds and mammals. The bias in relation to reintroduction programmes is surprising and indicates that managers working with invertebrates and amphibians are less willing and/or less able to publish their results than those working with mammals and birds. The reasons for this are unclear. The growth of the cumulative body of literature can be depicted by a sigmoid curve. Almost $40 \%$ of the items were scientific journal articles distributed across 335 journals. The large, ever-growing and dispersed evidence base results in an increased need for reviews, which must be systematic to minimize bias.
\end{abstract}

Keywords Bias, conservation biology, literature search, reintroduction, scientific literature, systematic review

\section{Introduction}

7 he allocation of resources to research on, and conservation of, the various taxonomic groups is influenced by the interests of society (Wilson et al., 2007) and public

BÁlint BAJOMI (Corresponding author) and ANDRÁs TAKÁcs-SÁNTA Centre for Environmental Science, Eötvös Loránd University of Sciences, Pázmány P. s. 1/A, 1117 Budapest, Hungary. E-mail bb@greenfo.hu

Andrew S. Pullin and Gavin B. Stewart* Centre for Evidence-Based Conservation, School of the Environment and Natural Resources, Bangor University, Gwynedd, UK

${ }^{*}$ Current address: Centre for Reviews and Dissemination, University of York, York, UK

Received 29 April 2009. Revision requested 10 June 2009.

Accepted 13 August 2009. opinion. In the USA, for example, birds, mammals and fish have a more positive social image than reptiles, amphibians, invertebrates or micro-organisms amongst the general public (Czech et al., 1998). Multiple factors are needed to explain how humans assign value to species: complexity, size, accessibility, degree of anthropomorphism, edibility and cultural influences (Wilson et al., 2008). One possible factor is phylogenetic distance between each group and the human lineage, which can be measured, for example, by the age since divergence. An inverse relationship exists between the number of scientific articles per species and phylogenetic distance from humans (Wilson et al., 2008; Martin-Lopez et al., 2009).

These factors result in a taxonomic bias in scientific research and conservation activities, which becomes evident when looking at the distribution of articles in journals dealing with conservation biology and related fields (e.g. behaviour, ecology and evolution). Vertebrates, especially mammals and birds, are greatly over-represented relative to their number of species (Bonnet et al., 2002; Clark \& May, 2002; Báldi \& McCollin, 2003; Fazey et al., 2005; Lawler et al., 2006; Martin-Lopez et al., 2009). Taxonomic bias also pervades reintroduction programmes (Seddon et al., 2005) but, to our knowledge, no previous research has examined whether the proportions by taxon of conservation projects and the reporting of them in the literature correspond.

Conservation practitioners and scientists need to remain up to date with the conservation literature. Beyond taxonomic bias they face two other challenges: the quantity and scatter of the literature. Science is in an era of accelerated information accrual (Carneiro et al., 2008; Howe et al., 2008). During the 2oth century the number of peerreviewed academic journals grew continuously, with an annual growth rate of $3.3-4.7 \%$ (Mabe \& Amin, 2001) and the number of scientific articles increased concomitantly (Garfield, 2007). This information accrual is also occurring in conservation biology (Lawler et al., 2006).

Literature relevant to a subject can be scattered across many sources (Garg et al., 2006). Bradford's Bibliometric Law states that 'for any given discipline, if scientific journals are ranked in order of decreasing number of published studies, then the journal scatter can be characterized into a nucleus of a small number of journals particularly devoted to the subject, and then subsequent circumferential zones containing the same number of studies as the nucleus but published over an increasing number of journals' (Garg 
et al., 2006). Article numbers in the nucleus and succeeding zones will be as $1: \mathrm{n}: \mathrm{n}^{2}$ (Bradford, 1934), $1: \mathrm{n}$ being the proportion of papers published in the first and second zone. 'For example, when a ranked journal list is divided into three zones with an equal number of studies in each zone, the number of journals in the nucleus (first zone) and two succeeding zones (second and third zone) follows a distribution of $1: n: n^{2}$ (Garg et al., 2006).

To examine the prevalence of these problems in conservation biology we took the topic of animal reintroductions as an example. We addressed several questions. To examine taxonomic bias we compared the taxonomic distribution of the reintroduction literature (1) with numbers of reintroduction programmes across taxa, and (2) with the proportions in the general conservation literature. Then, to investigate the quantity and scatter of the literature on animal reintroductions we examined (3) the extent of the published literature, (4) the number of new publications per year, (5) the distribution of publications according to their type (journal articles, conference proceedings, books, etc.), (6) the distribution of articles across journals, (7) whether this distribution follows Bradford's Bibliometric Law, and (8) the 10 journals publishing the most articles on reintroductions.

\section{Methods}

We collected literature following a protocol designed for a systematic review of the factors affecting the success of animal reintroductions (Bajomi, 2007). We attempted to search the relevant literature exhaustively using online databases and catalogues, and also included bibliographies and BB's collection of reintroduction articles.

\section{Search strategy}

Searches were performed in eight online databases and catalogues (Table 1), with the citations retrieved from each search recorded in an EndNote (Thomson Reuters, New York, USA) database. Searches used English search terms

TABLE 1 Databases and catalogues used for the bibliographic searches.

\begin{tabular}{ll}
\hline Database & Internet address \\
\hline ISI Web of Knowledge & $\mathrm{http} / /$ www.isiknowledge.com \\
Scopus & $\mathrm{http} / /$ www.scopus.com \\
ScienceDirect & $\mathrm{http} / /$ www.sciencedirect.com \\
Copac & $\mathrm{http} / / /$ copac.ac.uk \\
Index of Theses Online & $\mathrm{http} / /$ www.theses.com \\
Science Conference & $\mathrm{http} / /$ www.osti.gov/scienceconferences \\
$\quad \begin{array}{l}\text { Proceedings } \\
\text { Science.gov }\end{array}$ & $\mathrm{http} / /$ www.science.gov \\
ISI Proceedings & $\mathrm{http} / /$ www.isiknowledge.com \\
\hline
\end{tabular}

(Table 2) and covered published literature to February 2008. As Seddon et al. (2007) found that the four top journals for reintroduction-related articles were Biological Conservation, Conservation Biology, Journal of Wildlife Management and Oryx, these journals were searched separately for the term 'reintroduction' in Web of Science. The 'times cited' option in ISI Web of Knowledge was used for three highly cited articles (Griffith et al., 1989; Short et al., 1992; Snyder et al., 1996) to retrieve relevant articles citing these articles.

The following inclusion criteria were applied by reading titles and abstracts: (1) relevant subject(s): locally extinct animal species (invertebrates, amphibians, reptiles, birds and mammals), (2) types of intervention: reintroductions for conservation purposes, including captive breeding, relocations and translocations, and (3) types of study: all studies presenting primary data about a relevant subject and intervention as well as relevant secondary and theoretical studies. Articles not meeting these criteria were excluded from the database.

\section{Bibliographies}

We integrated into the database the following bibliographies: (1) the 454 peer-reviewed articles published during 1990-2005 cited by Seddon et al. (2007), (2) the IUCN Reintroduction Specialist Group Literature Database with 1,789 references (Soorae, 2002), which is the catalogue of the Group's library, (3) Kenyon (1995), which has 633 citations, and (4) Armstrong (2008), which has 197 citations.

The 26 volumes of Re-introduction News (the publication of the IUCN Reintroduction Specialist Group) were treated separately. Total number of pages, number of articles per year and total number of articles for each taxonomic category (invertebrates, fish, amphibians,

TABle 2 English language search terms used. Some search engines do not allow the use of a wildcard (e.g. reintroduc ${ }^{\star}$ ). In such cases the wildcard term was replaced by the appropriate term indicated by the superscripted numbers.

\begin{tabular}{l} 
Search terms \\
\hline reintroduc $^{\star 1}$ OR re-introduc $\left.{ }^{*^{2}}\right)$ AND species \\
translocat ${ }^{3}$ AND conservation AND species \\
relocat $^{*^{4}}$ AND conservation \\
'captive breeding' AND reintroduc ${ }^{\star 1}$ \\
'captive bred' AND reintroduc ${ }^{\star 1}$ \\
'back into the wild' \\
('captive rearing' OR 'captive-reared') AND reintroduc ${ }^{\star 1}$ \\
${ }^{1}$ reintroduction OR reintroductions OR reintroduced OR reintroducing \\
${ }^{2}$ re-introduction OR re-introductions OR re-introduced OR re-introducing \\
${ }^{3}$ translocation OR translocations OR translocated OR translocating \\
${ }^{4}$ relocation OR relocations OR relocated OR relocating
\end{tabular}


reptiles, birds, mammals and articles dealing with several taxa) were tallied. Only reports on reintroduction programmes were included from Re-introduction News.

In the final database all duplicate references were removed. Most of the database entries were for English publications, with a small number of French, Spanish, German and Hungarian references that came mostly from the bibliographies. All references were grouped in EndNote according to taxonomic category (invertebrates, fish, amphibians, reptiles, birds, mammals and articles dealing with several taxa) and reference type (book, book section, conference paper, electronic source, journal article, magazine article, manuscript, newspaper article, report, specialist newsletter article, thesis, and other).

\section{Data analyses}

We calculated descriptive statistics to examine the extent and distribution of the literature. To examine whether the scattering of journals was specific to this area or followed a more general pattern, we used Bradford's Bibliometric Law (Bradford, 1934). We divided all the articles into three zones, each with approximately equal numbers of articles and examined whether the resulting ratio of journal number is close to the predicted distribution of $1: n: n^{2}$.

To compare the taxonomic distribution of reintroduction articles with that of wild species, the general conservation literature, and reintroduction programmes, we used a $\chi^{2}$ analysis. We calculated Pearson residuals for each group to indicate the direction of bias following the methods of Seddon et al. (2005).

\section{Results}

\section{What is the extent of the reintroduction literature?}

The final database contained 3,826 publications related to animal reintroductions. Summing the total number of pages of the references indicated that the extent of this literature is at least 29,290 pages (articles with no page number information in the bibliographies were assumed to have one page and thus the sum is an underestimate.) A part of this body of literature is not purely scientific because $14 \%$ of the references come from magazine articles (e.g. BBC Wildlife), and books and specialist newsletters vary in their level of scientific ambition (see below).

Before the 1960s publications on reintroduction were scarce but started to increase by the end of that decade. Exponential growth is evident up to a peak in 1995, with 244 publications in that year. Since then the annual number of publications has varied but almost every year $>100$ items are published. The growth of this cumulative body of literature can be depicted by a sigmoid curve (Fig. 1).

\section{Where is the literature published?}

We divided the literature into 12 categories (Table 3). The largest category, accounting for $38 \%$ of the publications, is scientific journals. The majority of the specialist newsletter articles were published in Re-introduction News. There was also a large number of magazine articles from periodicals such as BBC Wildlife and New Scientist (most of these references were imported from Soorae, 2002).

Scientific journal articles were scattered across 335 journals (Fig. 2). About half (51\%) of the articles were published in 20 journals and the remaining in a further 315 journals. Examining conformity to Bradford's Bibliometric Law, Zone 1 contained seven journals (497 studies), Zone 2, 43 journals (482 studies), and Zone 3, 285 journals (467 studies). The resulting ratio of journal number is $1: 6: 41$, close to the distribution of $1: 6: 6^{2}$ (i.e. 36) predicted by Bradford's Law.

The top 11 journals for reintroduction studies are presented in Table 4 (we present 11 because the 1oth and 11th had the same number of articles). The first four journals are the same as those identified by Seddon et al. (2007).

\section{Is the literature taxonomically biased?}

As we expect from previous reviews of the reintroduction literature there is a significant difference between the taxonomic distribution of known animal species and reintroduction-related publications $\left(\chi^{2}=273,929, \mathrm{df}=5\right.$, $\mathrm{P}<0.001$; Table 5). Nearly half of the publications dealt with mammals and $27 \%$ with birds (Fig. 3). Only $3 \%$ concerned invertebrate reintroductions despite the fact that the overwhelming majority of animal biodiversity comprises invertebrates, especially insects (IUCN, 2008). When looking at two subsets of our database: journal articles, books and book sections together and the grey literature category comprising all other types, it is evident that journals and books tend to publish more on general reintroduction topics and are less prone to this bias than the grey literature (Fig. 3).

Two separate elements result in this bias. Firstly, the bias towards vertebrates in the number of reintroduction projects (Seddon et al., 2005). Secondly, the significant bias between the distribution of projects and that of related publications $\left(\chi^{2}=789, \mathrm{df}=5, \mathrm{P}<0.001\right.$; Table 5). A disproportionately small number of projects is undertaken on invertebrates but an even smaller number is published. The resulting overall bias is significantly greater than that found by Clark \& May (2002) in the general conservation biology literature $\left(\chi^{2}=727.28, \mathrm{df}=5, \mathrm{P}<0.001\right.$; Table 5$)$. Mammals are more represented in reintroduction publications than in the overall conservation literature, whereas the proportion of articles on other reintroduced taxa is lower. 


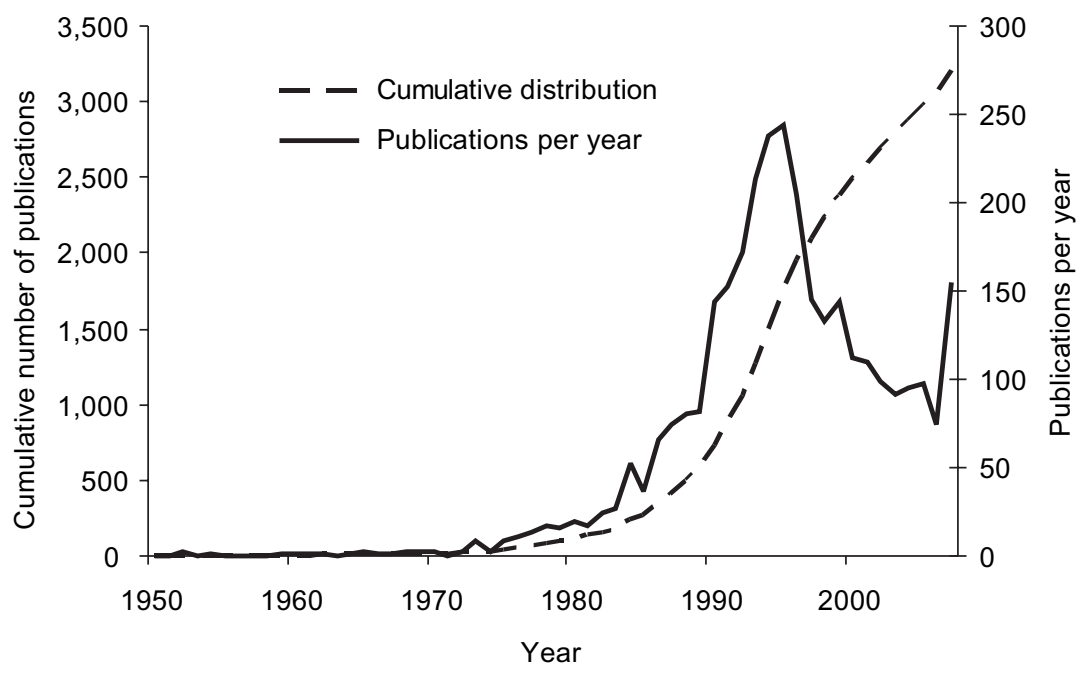

FIg. 1 Number, and cumulative distribution, of publications on reintroduction from 1950 to 2007.

\section{Discussion}

\section{Extent of the literature}

Our data show that a large amount of literature has been published on reintroductions and that it is scattered amongst many journals, books, conference proceedings and other types of literature. It is therefore difficult for conservation biologists and practitioners to follow the growth of the literature relevant to conservation interventions. As conformity to Bradford's Law indicates, scanning the top seven reintroduction journals regularly will reveal only one-third of the journal articles published on the topic. The remaining studies are found in a wide range of journals (Garg et al. 2006).

The level of importance of various kinds of publications for conservationists is variable: ideally, managers should search for and read quality-assured outputs and specialist newsletter articles rather than other types of literature.

TABLE 3 Distribution of the reintroduction literature by type of publication, in decreasing order of frequency.

\begin{tabular}{lc}
\hline Reference type & No. of references (\%) \\
\hline Journal article & $1,446(38)$ \\
Specialist newsletter article & $610(16)$ \\
Magazine article & $535(14)$ \\
Other & $447(12)$ \\
Conference paper & $198(5)$ \\
Book section & $191(5)$ \\
Report & $156(4)$ \\
Manuscript & $88(2)$ \\
Book & $74(2)$ \\
Thesis & $45(1)$ \\
Newspaper article & $29(0.7)$ \\
Electronic source & $7(0.2)$ \\
Total & $3,826(100)$ \\
\hline
\end{tabular}

Unfortunately, however, managers often lack access to the peer-reviewed literature and thus have to rely on other sources of information.

There is also a degree of redundancy in the outputs: a conservation programme can yield a report, a conference abstract, a popular science piece, a newsletter article, a manuscript and a peer-reviewed article but only the last one should be used to obtain the appropriate qualityassured information. However, many programmes do not produce peer-reviewed articles and in these cases practitioners again have to rely on other sources.

To help conservation managers and to examine the effectiveness of conservation interventions, reviews and synthesis of evidence are needed, with the results available to practitioners. The regular production and dissemination of systematic reviews, a method already widely used in the health services, has been proposed as a solution to these problems (Pullin et al., 2004; Pullin \& Stewart, 2006).

\section{Growth of the body of literature}

There is a marked difference between our estimate of the growth of the literature (with a peak in 1995 and a decrease thereafter; Fig. 1) and Fig. 1. of Seddon et al. (2007) showing exponential growth until 2006. However, Seddon et al. (2007) took into account only peer-reviewed articles, and when we examined only the peer-reviewed subset of our database we found the same exponential pattern. The difference between the two studies therefore comes from the non-peer-reviewed literature, found mostly in the bibliographies that we integrated into the database. This can perhaps be attributed to the fact that the bibliographies covered different time periods. Whilst bibliographies are important because they uncover articles that remain unnoticed when only search engines are used, the temporal distribution of their references can be biased. 


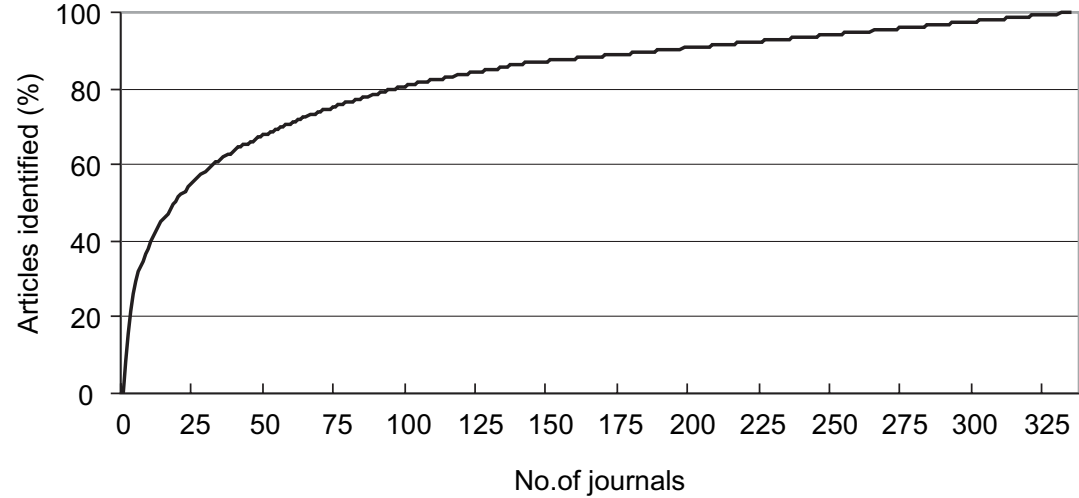

FIG. 2 Distribution of 1,446 reintroductionrelated articles across 335 journals, with journals ordered by the number of published papers.

\section{Taxonomic bias}

The overwhelming majority of publications on reintroduction deal with mammals and birds. This bias has arisen because both the selection of species for reintroduction and publication of the results are biased. The bias towards mammals and birds is explained by the social image of different taxa. The second element of the bias has not previously been reported and is more difficult to interpret. A number of questions arise from this that require further research: Are managers working with insects and amphibians less willing and/or less able to publish their results? Are there more reintroduction failures for these taxa? Are there fewer taxonomic specialist publication outlets for work on these taxa? Does the preponderance of mammalogists and ornithologists compared with entomologists or herpetologists influence the likelihood of specialist involvement in reintroduction research?

A possible explanation is that editors and peer reviewers disfavour some taxa in an unconscious process described as taxonomic chauvinism (Bonnet et al., 2002). Bonnet et al.

TABLE 4 The 11 journals containing the most articles on reintroductions (out of a total of 335 journals containing 1,446 articles).*

\begin{tabular}{lc}
\hline Journal & No. of articles (\%) \\
\hline Biological Conservation & $121(8)$ \\
Conservation Biology & $103(7)$ \\
Oryx & $91(6)$ \\
Journal of Wildlife Management & $61(4)$ \\
International Zoo Yearbook & $51(4)$ \\
Animal Conservation & $36(2)$ \\
Endangered Species Update & $34(2)$ \\
Wildlife Society Bulletin & $32(2)$ \\
Journal of Zoo and Wildlife Medicine & $23(2)$ \\
Dodo, Journal of the Jersey Wildlife & $22(2)$ \\
$\quad$ Preservation Trust & \\
Zoo Biology & $22(2)$ \\
Total & $596(41)$
\end{tabular}

${ }^{\star}$ Full list of titles is available from the corresponding author
(2002) demonstrated that studies on ectothermic vertebrates (i.e. fish, amphibians and reptiles) have to be framed more conceptually than those on endothermic vertebrates (birds and mammals) for a similar probability of publication, most likely because reviewers are biased towards their own study organisms.

Evaluation of subject organisms has been used as a proxy measure to quantify research bias in conservation (Clark \& May, 2002). Our results show that this proxy displays the general trends, but not the exact proportions, because it is biased itself. The scientific literature of journals and books is less prone to bias than grey literature.

\section{Language and outcome bias}

It was beyond the scope of our research to cover the literature extensively in languages other than English. The publications we collected in our database constitute the most visible part of the international literature, English being the language of international scientific communication. But significant publications do exist in other languages; therefore, even the large number of publications that we located is probably an underestimate. Language bias is well documented in medicine (Scholey \& Harrison, 2003) but has received little attention in conservation science.

It has been demonstrated in medicine that clinical trials with positive results were more likely to be published than those with negative results (Easterbrook et al., 1991; Lee et al., 2008). A similar bias also occurs in ecology and evolution (Jennions \& Moller, 2002; but see Koricheva, 2003). Outcome bias probably also occurs in the conservation literature because managers of successful programmes are more willing to publish their results than those failing to achieve their objectives (Teixeira et al., 2007).

Partly because of these biases many conservation projects remain undocumented or poorly documented in the published literature (Fischer \& Lindenmayer, 2000; Standovár, 2001; Márkus, 2004; Pullin et al., 2004). Different kinds of publications represent different levels of 
TABLE 5 Number of reintroduction-related articles across six taxonomic groups, and the distribution of described species, reintroduction projects and conservation publications across the same groups. Numbers of publications expected were calculated from the total number of publications and the relevant distribution. Absolute residuals are the differences between observed and expected numbers. Pearson residuals are standardized for direct comparison across taxa, and squares of Pearson residuals were used to calculate the $\chi^{2}$ values (see text for details, and Seddon et al., 2005). A group having a positive residual is over-represented in the reintroduction literature, whereas a negative residual indicates under-representation. The total number of publications is less than the number mentioned in the text and Table 3 because here we excluded articles dealing with several taxa.

\begin{tabular}{|c|c|c|c|c|c|c|c|}
\hline & Invertebrates & Fish & Amphibians & Reptiles & Birds & Mammals & Total \\
\hline $\begin{array}{l}\text { No. of reintroduction } \\
\text { publications (our } \\
\text { database) }\end{array}$ & 132 & 139 & 101 & 191 & 1,019 & 1,854 & 3,436 \\
\hline \multicolumn{8}{|l|}{ Described species } \\
\hline $\begin{array}{l}\text { No. of described } \\
\text { species (IUCN, 2008) }\end{array}$ & $1,232,384$ & 30,700 & 6,347 & 8,734 & 9,990 & 5,488 & $1,293,643$ \\
\hline $\begin{array}{l}\text { No. of publications } \\
\quad \text { (expected) }\end{array}$ & 3,273 & 82 & 17 & 23 & 27 & 15 & 3,436 \\
\hline Absolute residual & $-3,141$ & 57 & 84 & 168 & 992 & 1,839 & \\
\hline $\begin{array}{l}\text { Square of Pearson } \\
\text { residual }\end{array}$ & 3,015 & 40 & 420 & 1,214 & 37,122 & 232,119 & 273,929 \\
\hline \multicolumn{8}{|l|}{ Reintroduction projects } \\
\hline $\begin{array}{l}\text { No. of projects } \\
\quad \text { (Seddon et al., 2005) }\end{array}$ & 65 & 20 & 24 & 70 & 138 & 172 & 489 \\
\hline $\begin{array}{l}\text { No. of publications } \\
\quad \text { (expected) }\end{array}$ & 457 & 141 & 169 & 492 & 970 & 1,209 & 3,436 \\
\hline Absolute residual & -325 & -2 & -68 & -301 & 49 & 645 & \\
\hline $\begin{array}{l}\text { Square of Pearson } \\
\text { residual }\end{array}$ & 230.88 & 0.02 & 27.13 & 184.03 & 2.51 & 344.68 & 789.25 \\
\hline \multicolumn{8}{|l|}{ Conservation publications } \\
\hline $\begin{array}{l}\% \text { of conservation } \\
\text { publications (Clark \& } \\
\text { May, 2002) }\end{array}$ & 13.6 & 6.8 & 5.1 & 6.8 & 33.3 & 34.2 & 100.0 \\
\hline $\begin{array}{l}\text { No. of reintroduction } \\
\text { publications (expected) }\end{array}$ & 468 & 235 & 176 & 235 & 1,146 & 1,175 & 3,436 \\
\hline Absolute residual & -336 & -96 & -75 & -44 & -127 & 679 & \\
\hline $\begin{array}{l}\text { Square of Pearson } \\
\text { residual }\end{array}$ & 241.61 & 39.25 & 32.16 & 8.26 & 14.05 & 391.95 & 727.28 \\
\hline
\end{tabular}

difficulty for the publication of data on a conservation programme. This can affect the process of systematic or other reviewing, which makes it more difficult to detect general trends and formulate new theories. It is important, therefore, to publish the results of every conservation programme. The situation would improve if funding bodies required recipients of funds to evaluate and publish the results of management actions. This would help overcome taxonomic bias as well, coercing managers working on taxa less apparent in the literature to publish their results.

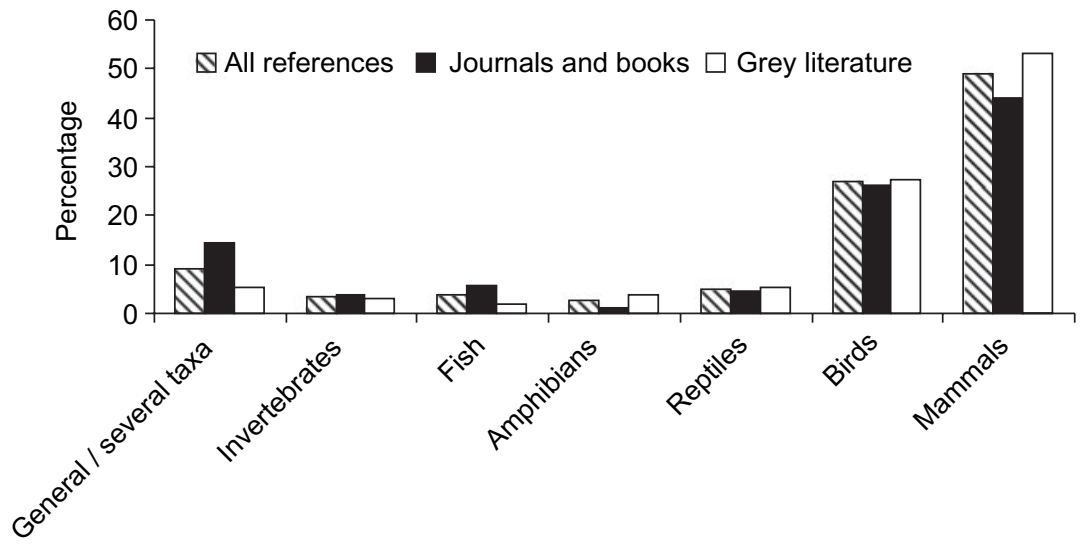

FIG. 3 Percentage frequency distribution of reintroduction-related articles by taxonomic group and literature category. 


\section{Conclusions}

There is a bias towards mammals and birds in the publication of the results of reintroduction programmes, and further research is needed to clarify the drivers behind this bias. Despite the growth in the number of reintroduction projects, the dispersed and biased nature of the literature means that we may be failing to accumulate a reliable evidence base to underpin decision making. To assure a reliable picture of conservation activities, managers should try to publish the outcome of every programme and editors and peer reviewers should lessen the bias in their journals. When attempting to review and synthesize the accumulated literature it is important to be aware of biases, such as those we have documented here, and to account for them in review methodology.

\section{Acknowledgements}

We thank two anonymous referees and Gábor Vida, Helen Bayliss, Diana Bowler, Lisette Buyung-Ali, Tam Kabat, Teri Knight and Ferenc Jordán for their comments and help, and Philip J. Seddon for providing a list of reintroductionrelated articles. BB thanks Mihályné Szepesi for her financial support and an anonymous referee who commented on the protocol of this research.

\section{References}

Armstrong, D. (2008) Publications on Reintroduction in Oceania. IUCN Reintroduction Specialist Group, Oceania Section, Palmerston North, New Zealand. Http://www.massey.ac.nz/ darmstro/publications.htm [accessed 4 February 2010].

B AJOMI, B. (2007) Factors Influencing the Success Rate of Reintroduction of Endangered Animal Species. Systematic Review No. 29. Centre for Evidence-based Conservation, Bangor, UK. Http:// www.environmentalevidence.org/Documents/Protocol29.pdf [accessed 30 January 2009].

BÁldi, A. \& McCollin, D. (2003) Island ecology and contingent theory: the role of spatial scale and taxonomic bias. Global Ecology and Biogeography, 12, 1-3.

Bonnet, X., Shine, R. \& Lourdais, O. (2002) Taxonomic chauvinism. Trends in Ecology \& Evolution, 17, 1-3.

BRADFORD, S.C. (1934) Sources of information on specific subjects. Engineering, 137, 85-86.

Carneiro, F.M., Nabout, J.C. \& Bini, L.M. (2008) Trends in the scientific literature on phytoplankton. Limnology, 9, 153-158.

Clark, J.A. \& MAY, R.M. (2002) Taxonomic bias in conservation research. Science, 297, 191-192.

Czech, B., Kausman, P.R. \& Borkhataria, R. (1998) Social construction, political power, and the allocation of benefits to endangered species. Conservation Biology, 12, 1103-1112.

Easterbrook, P.J., Gopalan, R., Berlin, J.A. \& Matthews, D.R. (1991) Publication bias in clinical research. The Lancet, 337, $867-872$.

Fazey, I., Fischer, J. \& Lindenmayer, D.B. (2005) What do conservation biologists publish? Biological Conservation, 124, $63-73$.
Fischer, J. \& Lindenmayer, D.B. (2000) An assessment of the published results of animal relocations. Biological Conservation, $96,1-11$.

Garfield, E. (2007) Charting the Growth of Science. Presented at the Chemical Heritage Foundation, Philadelphia, USA. Http://garfield.library.upenn.edu/papers/chartinggrowthofscience2007.pdf [accessed 4 February 2010].

Garg, A.X., Iansavichus, A.V., Kastner, M., Walters, L.A., Wilczynski, N., McKibвon, K.A. et al. (2006) Lost in publication: half of all renal practice evidence is published in nonrenal journals. Kidney International, 70, 1995-2005.

Griffith, B., Scott, J.M., Carpenter, J.W. \& Reed, C. (1989) Translocation as a species conservation tool: status and strategy. Science, $245,477-480$.

Howe, D., Costanzo, M., Fey, P., Gojobori, T., Hannick, L., Hide, W. et al. (2008) Big data: the future of biocuration. Nature, $455,47-50$.

IUCN (2008) IUCN Red List of Threatened Species, Summary Statistics. IUCN, Gland, Switzerland. Http://www.redlist.org/ static/stats [accessed 15 February 2009].

Jennions, M.D. \& Moller, A.P. (2002) Publication bias in ecology and evolution: an empirical assessment using the 'trim and fill' method. Biological Reviews, 77, 211-222.

Kenyon, K.A. (1995) Reintroduction of Captive Animals into Their Native Habitat: A Bibliography. National Zoological Park Branch, Smithsonian Institution Libraries, Washington, DC, USA. Http:// www.nal.usda.gov/awic/zoo/reintrod.pdf [accessed 4 February 2010].

KorICHEVA, J. (2003) Non-significant results in ecology: a burden or a blessing in disguise? Oikos, 102, 397-401.

Lawler, J.J., Aukema, J.E., Grant, J.B., Halpern, B.S., Kareiva, P., Nelson, C.R. et al. (2006) Conservation science: a 20-year report card. Frontiers in Ecology and the Environment, 4, 473-480.

Lee, K., B Aсchetті, P. \& Sim, I. (2008) Publication of clinical trials supporting successful new drug applications: a literature analysis. PLoS Medicine, 5, elg1.

Mabe, M. \& Amin, M. (2001) Growth dynamics of scholarly and scientific journals. Scientometrics, 51, 147-162.

MÁrKUS, F. (2004) Gerinces állatfajok visszatelepítésének természetrajza Magyarországon, 1970-től napjainkig. Természetvédelmi Közlemények, 11, 359-369. [in Hungarian, with English abstract]

Martin-Lopez, B., Montes, C., Ramirez, L. \& Benayas, J. (2009) What drives policy decision-making related to species conservation? Biological Conservation, 142, 1370-1380.

Pullin, A.S., Knight, T.M., Stone, D.A. \& Charman, K. (2004) Do conservation managers use scientific evidence to support their decision-making? Biological Conservation, 119, 245-252.

Pullin, A.S. \& Stewart, G.B. (2006) Guidelines for systematic review in conservation and environmental management. Conservation Biology, 20, 1647-1656.

Scholey, J.M. \& Harrison, J.E. (2003) Publication bias: raising awareness of a potential problem in dental research. British Dental Journal, 194, 235-237.

Sedion, P.J., Armstrong, D.P. \& Maloney, R.F. (2007) Developing the science of reintroduction biology. Conservation Biology, 21, 303-312.

Seddon, P.J., Soorae, P.S. \& Launay, F. (2005) Taxonomic bias in reintroduction projects. Animal Conservation, 8, 51-58.

Short, J., Bradshaw, S.D., Giles, J., Prince, R.I.T. \& Wilson, G.R. (1992) Reintroduction of macropods (Marsupialia, Macropodoidea) in Australia-a review. Biological Conservation, 62, 189-204.

SNyder, N.F.R., DerRickson, S.R., Beissinger, S.R., Wiley, J.W., Smith, T.B., Toone, W.D. \& Miller, B.J. (1996) Limitations of 
captive breeding in endangered species recovery. Conservation Biology, 10, 338-348.

Soorae, P.S. (2002) The IUCN/SSC Re-Introduction Specialist Group (RSG) Literature Database. IUCN Reintroduction Specialist Group, Abu Dhabi, United Arab Emirates.

STANdovár, T. (2001) A természetvédelmi biológia helyzete Magyarországon egy országos felmérés alapján. Természetvédelmi Közlemények, 9, 1-14.

Teixeira, C.P., de Azevedo, C.S., Mendl, M., Cipreste, C.F. \& YounG, R.J. (2007) Revisiting translocation and reintroduction programmes: the importance of considering stress. Animal Behaviour, 73, 1-13.

Wilson, J.R.U., Proches, S., Braschler, B., Dixon, E.S. \& Richardson, D.M. (2007) The (bio)diversity of science reflects the interests of society. Frontiers in Ecology and the Environment, 5, 409-414.

Wilson, J.R.U., Proches, S., Braschler, B., Dixon, E.S. \& Richardson, D.M. (2008) Organismal complexity is an in- dicator of species existence value-the authors reply. Frontiers in Ecology and the Environment, 6, 299-300.

\section{Biographical sketches}

BÁLINT BAJOMI analysed the reasons for the failure of the whiteheaded duck Oxyura leucocephala reintroduction programme in Hungary and later began a systematic review of the factors influencing the success of animal reintroductions. ANDrew S. Pullin is interested in developing the concept of evidence-based conservation to improve the quality of decision making and effective use of resources in conservation policy and practice. GAVIN B. STEWART, an applied ecologist and botanist, is primarily interested in research synthesis methods. András TAKÁCs-SÁnta is dealing with various issues concerning the human transformation of the biosphere, especially the social background of this transformation. 